\title{
Health Management System of Residential Quarters
}

\author{
WANG Xiaopeng \\ Liaoning Geology Engineering Vocational College, Liaoning Dandong, 118000, China \\ wxp_1116@163.com
}

Keywords: health management; residential quarters; JSP; SQL Server database

\begin{abstract}
This work designed and implemented a health management system of residential quarters based on JSP and SQL Server database. The system takes the residential quarters as the service object. By using JSP as the development language and SQL Server as the database management system, a personal health management system with $\mathrm{B} / \mathrm{S}$ structure based on Web technology is achieved under MyEclipse software environment. Medical information of personal can be stored in the database, thus the suggestion of the personal health information such as diet, living and medial, etc. can be obtained by analyzing his or her historical data. Furthermore, important knowledge of life habits, health status and trends in the development of the disease can be given through data mining in database. The system has an important role in promoting medical and health management for residential quarters and it can be widely used.
\end{abstract}

\section{Introduction}

Personal health management system is a complex man-machine interaction system which involves information science, data computing and computer technology [1]. The system can help users to strengthen the health management, determine the personal health maintenance plan and conduct personal life behavior guidance and management, which achieves the disease prevention and monitoring. Furthermore, the health management system can timely and dynamic tracking of the user's health status and provide a health warning when needed [2]. Health management is a new thing at present [3]. With the progress of society and the improvement of the people's living standard, the awareness of the health of the people is also increasing. Diseases prevention and health care takes more and more people's attention. With the wide application of the rapid development of IT technology and Internet, the computer application has penetrated into every field of social life. With the expansion of the scope and scale of the hospital information system, data processing mode, which takes the patient information as the center, has become the main research subject of computer application. Under the requirements of improving human health level, how to apply the computer to the medical information development, and to diagnose and daily health management services for the individual is a subject of computer science research personnel. Although some companies have reflected the idea of health management in different degrees, most of them are standing in the position of medical institutions, which take the disease as the center and provide health management of special high income people from the perspective of the development of medical market. These companies belong to the increase of medical needs and lie on the promotion of the medical consumption of aristocratic management ideals, which only serve for the appropriate class that are mostly high income people. Therefore, these companies cannot meet the general public health services needs for effectiveness and save money. For example, the domestic leading health management companies such as Aikangguobin, which goal is to The goal is to provide health management services to enterprises, families and individuals, and to provide medical, medical, family doctor, chronic disease management and so on. However, its charge is also high and cannot meet the needs of different groups of people in health management.

In this case, it is necessary to develop health management system for the general population. Hereby we proposed a health management system of residential quarters. The system takes the residential quarters as the service object. By using JSP as the development language and SQL Server as the database management system, a personal health management system with B/S structure [4] 
based on Web technology is achieved under MyEclipse software environment. From requirement analysis, system design and function model implement, a complete and practical health management system is presented.

\section{Requirement of the system}

\section{Feasibility analysis}

The feasibility of the health management system of residential quarters is analyzed during the system design from four aspects, which are technical feasibility, economic feasibility, operation feasibility and law feasibility. The system development tool is MyEclipse software and SQL Server database, and the development language is Java, which mainly uses the J2EE technology. Java is an object-oriented programming language which is easy to learn and flexible and convenient. The software, database and technology used in the system development are very mature. Therefore, the completion of the system is completely feasible in technology. Today is the information age and the information management can make individual health management more systematic, rapid and comprehensive. Requirements for computer configuration of the health management system of residential quarters are not high. At present, even the low configuration computer in the market can meet the needs of the system. Therefore, it is complete feasibility in economy. System design and development must take into account the application of the users. The system is designed for residential quarters, so the system interface design must be simple and easy to use. Using $\mathrm{B} / \mathrm{S}$ structure can design a simple and easy to use interface, thus there is no difficulty for operation feasibility. Personal health management system is a management system which is developed by us, and it is a practical system. The development environment software and the use of the database is open source code. The development of this system is different from the development of ordinary system software, there is no infringement and other issues, and that is, the law is feasible. To sum up, it is feasible and necessary to establish a personal health management system.

\section{System user analysis}

The users of the health management system of residential quarters can be divided into three categories, which are ordinary users, administrator users and doctor users. The ordinary users can register a system account, by which the ordinary users can landing the health management system. The ordinary users can manage their own health information, including the daily record management, medical information management, health education activity records, health information browsing, doctor information browsing and online consulting doctors, etc. The administrator is responsible for managing the information of ordinary users and doctors, but also to publish health information for users to browse. Doctor users are responsible for processing and reply to the general user's consultation. The system user case diagram is shown in Tab.1.

Tab.1 The system user case diagram

\begin{tabular}{|c|c|}
\hline User type & Authority and responsibility \\
\hline Ordinary users & $\begin{array}{c}\text { Modify personal account password } \\
\text { Daily record management } \\
\text { Medical information input and management } \\
\text { Health education activity management } \\
\text { Online consulting doctor }\end{array}$ \\
\hline $\begin{array}{l}\text { Administrator } \\
\mathrm{S}\end{array}$ & $\begin{array}{l}\text { Modify personal account password } \\
\text { Member information management } \\
\text { Doctor information input and management } \\
\text { Publish the health information } \\
\text { Health information management }\end{array}$ \\
\hline Doctor users & $\begin{array}{l}\text { Handle user consultation } \\
\text { Reply the ordinary users }\end{array}$ \\
\hline
\end{tabular}




\section{Function module analysis and design idea}

According to the system user analysis, the health management system of residential quarters can be divided into three functional modules, which are ordinary user function module, administrator user function module and doctor user function module. Accordingly, the ordinary user module has the following functions: modify personal account password function, daily record management function and medical information input and management function, etc. The administrator user function module has the following functions: modify personal account password function, member information management function and doctor information input and management function, etc. The doctor user module has the following functions: handle user consultation function and reply the ordinary users function. For the practical application of the system, the system must have a simple and elegant interface, easy to use and friendly error operation tips. At the same time, the system must have a strong security to avoid the user's malicious operation.

The basic ideas of health management system of residential quarters design include the followings: (a) Using B/S model for development, which advantage is that the background and the foreground processing levels is clear, but also in line with the number of users have been accustomed to web users. (b) Using object-oriented development and design concept [5]. The premise of the using of object-oriented technology is a high and accurate abstraction of the whole system, which can guarantee the system has a good frame, and then bring the product the strong stability and the operation efficiency. (c) Using modular design method. The modular design requires that the whole system be divided into small modules, which is beneficial to the code's overload, simplifying the design and implementation process. (d) The system has a simple and convenient interface. A simple and friendly interface can be designed to facilitate the operation of the system by users. (e) Using speed priority principle. The most important an evaluation criterion of the personal health management system is speed, so in the system design process, the special process must achieve less resource and fast speed. (f) The system design is not only to highlight the focus, but also to consider the detailed and thoughtful. It is possible to improve the local expansion, so that the system is more suitable for the needs of users.

\section{The database analysis and design}

The design of the traditional database is generally through planning, requirement analysis, conceptual design, logical design and physical design [6]. The database of the health management system of residential quarters is designed according to the traditional database design process. The concept design is the database concept structure based on the data analysis, which is a database concept structure of the whole system from the bottom to the top. The concept design integrates the view and optimizes the results from the user's point of view. The conceptual structure design of the database is designed by using the entity relationship (E-R) model. The elements of E-R model are: entities, attributes and contact. The goal of concept design is to reflect the structure of the database, which is a concept model, which reflects the requirements of enterprise organization. The concept model is independent of the database logic structure and the DBMS, which is not dependent on the computer system. For example, the medical information entity E-R map is shown in Fig.1.

Database concept model is independent of any particular database management system. Therefore, the database concept model needs conversion according to the characteristic of the database management system to be used. That is the database concept model need to transform into the logical relationship model which is processed by computer. The E-R model transforms into the relationship database model should follow these principles: (a) Each entity should be transformed into a relationship. (b) All primary keys must be defined for non null. (c) For the two elements connection should be in accordance with the one to many, weak to real, one to one, many to many links to define a foreign key. According to the E-R model, the logical data structure of the personal health management system can be established. In the health management system of residential quarters, the data tables can be divided into the ordinary user table, daily record table, medical information table, health education activity information table, doctor information table, consulting information table, 
administrator information table. For example, the ordinary user table is shown in Tab.2. In the system, the database connects with JDBC and the DAO model is used for program.

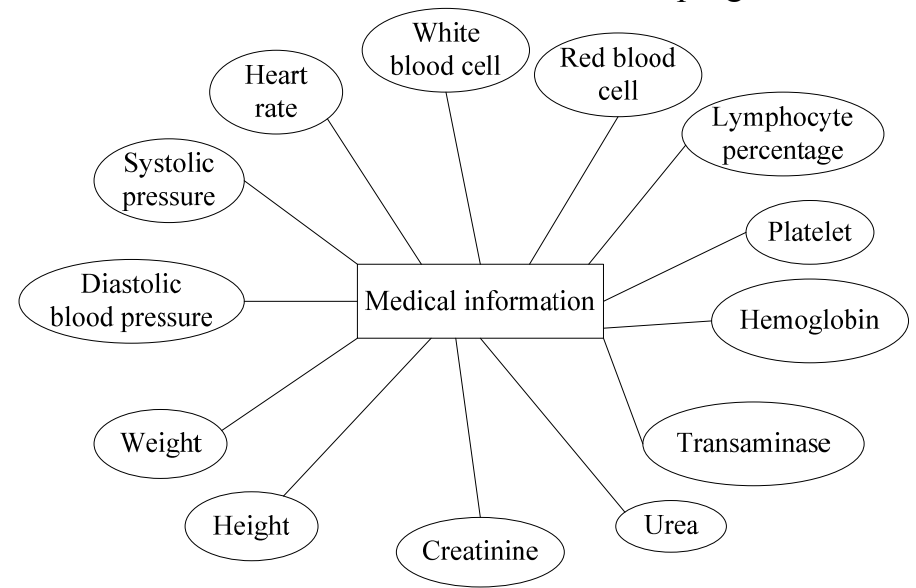

Fig.1 The medical information entity E-R map

Tab. 2 The ordinary user table

\begin{tabular}{|c|c|c|c|c|c|}
\hline Column & Data type & Length & Null & Primary Key & Remarks \\
\hline id & int & 4 & no & yes & No. \\
\hline loginName & varchar & 50 & no & no & account \\
\hline loginPass & varchar & 50 & no & no & password \\
\hline name & varchar & 50 & no & no & name \\
\hline sex & varchar & 50 & no & no & sex \\
\hline birthday & varchar & 50 & no & no & birthday \\
\hline
\end{tabular}

\section{Conclusion}

The health management system of residential quarters takes into account the needs of ordinary people to health management, which takes the residential residents as the service object. The system is designed and implemented by using the simple development tool, therefore, the low cost of development and use lead the system to suitable for the general population. However, there are still some problems to be solved, such as the privacy of user information, data security backup and data emergency recovery. With the further improvement of the system, its practical value will be gradually improved.

\section{References}

[1]P. SHU, J.G. CHEN. The design and implementation of student's dormitory management system in the construction of digital campus [J]. Journal of Wuhan Institute of Technology, 2008, 30(4): 108-111.

[2]F.E. ZENG, Q.H. ZHONG, J.M. ZHANG, et al. Mobile health monitoring system [J]. Microcomputer Information, 2011, 27(7): 149-151.

[3]D. MA, C.G. ZHOU, Z. WANG, et al. A web-based real-time and online analysis portal for personal health management [J]. Journal of Jilin University, 2010, 48(3): 461-463.

[4]F.L. WEI, H.C. TAO, L. HE. Design of personal health management system based on $3 \mathrm{G}$ [J]. Railway Computer Application, 2011, 20(10): 14-19.

[5]X.Y. CAO, Y.J. WANG, J. WANG, et al. Inner map service on android designed by rapid object-oriented process [J]. Journal of Navigation and Positioning, 2014, 2(4): 78-82.

[6]W. Y. CHEN. Design oriented-object relative database [J]. Journal of University of Electronic Science and Technology of China, 2002, 31(1): 53-56+75. 